\title{
Mycobacterium tuberculosis Uganda II is more susceptible to rifampicin and isoniazid compared to Beijing and Delhi/ CAS families
}

George W. Kasule ${ }^{1,2+}$, David P. Kateete ${ }^{3,4+}$ and Moses L. Joloba ${ }^{1,2,3,4^{*}}$

\begin{abstract}
Background: Mycobacterium tuberculosis Uganda family is the predominant cause of tuberculosis in Uganda. Reasons for this are not clear but are likely to be due to the rampant person-to-person transmission or delayed susceptibility of the organism to drugs during treatment, which may lead to continuous shedding of infectious bacilli, among others. The objective of this study was to determine in vitro, the susceptibility patterns of $M$. tuberculosis Uganda family compared with Beijing and Delhi/CAS, other M. tuberculosis sub-lineages that also circulate in Uganda but are not as prevalent. The comparisons were made after 10 days of exposure of the strains to Rifampicin and Isoniazid, the most important first-line anti-tuberculosis drugs.
\end{abstract}

Methods: Minimum inhibitory concentrations (MICs) for three Isoniazid- and Rifampicin-susceptible M. tuberculosis strains (Uganda II, Beijing and Delhi/CAS families) were determined by micro-dilution plate assay. Killing curves for each strain were deduced from colony forming units after exposure to Isoniazid and Rifampicin on days 0, 2, 4, 6, 8, and 10 under aerobic and oxygen-depleted conditions. Data were analyzed with GraphPad Prism 5 software.

Results: The MIC for Isoniazid was $0.05 \mu \mathrm{g} / \mathrm{ml}$ for M. tuberculosis Uganda II, and $0.03 \mu \mathrm{g} / \mathrm{ml}$ for M. tuberculosis Beijing and Delhi/CAS. Rifampicin MIC was $1 \mu \mathrm{g} / \mathrm{ml}$ for M. tuberculosis Uganda II, and $0.12 \mu \mathrm{g} / \mathrm{ml}$ for Beijing and Delhi/CAS. At low Rifampicin $(0.03-2.5 \mu \mathrm{g} / \mathrm{ml})$ and Isoniazid $(0.12-5 \mu \mathrm{g} / \mathrm{ml})$ concentrations under aerobic conditions, there was no significant difference in susceptibility patterns between $M$. tuberculosis Uganda II and Beijing or Delhi/CAS. However, at high Rifampicin $(5 \mu \mathrm{g} / \mathrm{ml})$ and Isoniazid $(1.25 \mu \mathrm{g} / \mathrm{ml})$ concentrations under oxygen-depleted conditions, M. tuberculosis Uganda II was more susceptible to the drugs compared with Beijing or Delhi/CAS families.

Conclusion: The predominance of $M$. tuberculosis Uganda II family as the main causative agent of tuberculosis in Uganda is not attributed to its susceptibility behavior to Isoniazid and Rifampicin. Probably, its predominance is due to differences in the immune defenses in the general population against the strains, given that Beijing and Delhi/ CAS families may have been introduced more recently. Further research beyond susceptibility to anti-tuberculosis drugs is required to fully explore tuberculosis strain predominance in Uganda.

Keywords: Mycobacterium tuberculosis Uganda family, Minimum inhibitory concentrations, Drug susceptibility, Time-killing-curves, Isoniazid, Rifampicin, Strain, Genotype, Aerobic, Oxygen depleted

\footnotetext{
* Correspondence: moses.joloba@case.edu

${ }^{\dagger}$ Equal contributors

${ }^{1}$ National Tuberculosis and Leprosy Program, Kampala, Uganda

${ }^{2}$ National TB Reference Laboratory, Kampala, Uganda

Full list of author information is available at the end of the article
} 


\section{Background}

Human tuberculosis is an important disease worldwide second only to HIV/AIDS as the greatest killer attributed to a sole infectious agent. Tuberculosis (TB) is caused by a group of closely related bacteria referred to as the "Mycobacterium tuberculosis complex" (MTBC) comprising Mycobacterium tuberculosis, Mycobacterium bovis, Mycobacterium bovis BCG, Mycobacterium africanum, Mycobacterium canettii, Mycobacterium caprae, Mycobacterium microtii and Mycobacterium pinnipedii [1, 2]. Although the MTBC are highly identical at DNA level, molecular genotyping data has revealed that genetic diversity in form of single nucleotide polymorphisms (SNPs), insertions \& deletions (InDels), etc., occurs among the MTBC strains, and maybe responsible for phenotypic differences in drug susceptibility, pathogenicity, host tropism, transmissibility, immune response, and geographical distribution of the strains $[1,3]$. In light of this, the MTBC are classified into seven lineages (Lineage 1 to 7 ) [1-3] globally distributed with some lineage-types being more predominant than others in certain geographical regions and human populations [2, 3]. Lineage 4 (Euro-American) is commonly found in Africa, America, and Europe while Lineage 2 (East-Asia) is prevalent in Asia [3]; all the seven human-adapted MTBC lineages do circulate in Africa where MTBC appears to have originated, accompanying human migrations over millennia [2].

$M$. tuberculosis Uganda is a sub-lineage of the $M$. tuberculosis lineage 4, the Euro- American lineage which is defined by RD 724 deletion [4-8]. The M. tuberculosis Uganda family comprises $M$. tuberculosis Uganda I and Uganda II subfamilies with the latter being more prevalent in Uganda [5, 7]. Asiimwe et al., 2008 [4], Nabyonga et al., 2011 [7], and more recently Ezati et al., 2014 [5], reported higher occurrence in Uganda of the M. tuberculosis Uganda subfamily (>70\%) compared with other genotypes combined (LAM, Delhi/CAS and Beijing families about $3 \%$ each). However, little is known about the mechanisms that are responsible for this predominance in Uganda. Other than chance, one possibility is that the transmission of $M$. tuberculosis Uganda family in Ugandan populations is influenced by the level of drug susceptibility compared to the less predominant strains.

Furthermore, M. tuberculosis has a long generation time and capacity for dormancy, where its low metabolic activity complicates treatment options [9]. The bacilli can be located in pulmonary cavities, empyema, pus, or solid caseous material, where penetration by antibiotics is difficult or the $\mathrm{pH}$ is sufficiently low to inhibit the activity of most antibiotics [10]. Indeed, animal and human clinical trials have led to the concept that there are different populations of bacteria present within the host $[11,12]$. Organisms in pulmonary cavities are thought to be multiplying in an aerobic environment and consequently behave in a way that can be mimicked by in vitro tests. Organisms located within caseous foci are in a milieu where the low $\mathrm{pH}$ is likely to inhibit the activity of agents such as aminoglycosides but provide the conditions necessary for pyrazinamide activity [13]. Bacteria found within macrophages probably exhibit occasional spurts of metabolism and may be in relatively microaerophilic conditions, where mycobacterial dormancy can be induced [13]. Organisms located within granulomas are in a milieu where the oxygen is depleted.

Most diagnostic susceptibility tests guiding TB treatment investigate metabolically active bacilli under static conditions and as such, they may not be informative with respect to time-kill kinetics of anti-TB drugs and the emergence of resistance in low metabolically active or even dormant mycobacterial cells [14]. The kinetics of antimicrobial activity is generally used to evaluate and compare new drugs and study differences and changes in the antimicrobial susceptibilities of clinically important bacterial isolates [15]. The time-killing-curve method has been used in many studies, since bacterial death is evaluated with more information by this method than by end-point methods. As a means of data analysis, mathematical modeling is anticipated to be a useful tool in describing and comparing kinetics, leading to quantitative appraisal of bactericidal effects [16]. The pharmacodynamics of TB treatment should be further explored, to prevent emergence of resistance, treatment failure, relapse of infection [14] and determine the drug response of different genotypes.

In this study, we used time-kill-kinetics of Rifampicin and Isoniazid, the most important first-line anti-TB drugs, against selected strains under aerobic and oxygendepleted conditions, and determined the response of $M$. tuberculosis Uganda family to drugs, and whether this response might better explain its successful predominance in Uganda.

\section{Methods}

\section{Study site and setting}

This was a laboratory-based study conducted at the Uganda National Tuberculosis Reference Laboratory (NTRL) and the Medical \& Molecular Laboratory of the Department of Medical Microbiology, College of Health Sciences, Makerere University. The NTRL is a fully equipped Biosafety Level 3 Laboratory where TB culture is routinely done. Molecular tests to confirm Mycobacterium isolates to species level, as well as strain families, were performed at the Medical \& Molecular Laboratory.

\section{Isolates and drug susceptibility testing}

Mycobacterium tuberculosis isolates were obtained from the Joint Clinical Research Centre (JCRC), Kampala. Drug susceptibility testing was previously performed at 
the JCRC and the isolates were found to be susceptible to both Isoniazid and Rifampicin. The isolates were previously confirmed to species level through Region of Difference PCR analysis [4], and genotyped by MIRUVNTR to confirm they were $M$. tuberculosis Beijing, Uganda II, and Delhi/CAS families [7, 17].

At NTRL, the retrieved isolates (Beijing, Uganda II and CAS/Delhi) were sub-cultured by incubating at $37^{\circ} \mathrm{C}$ for 21 days on Middlebrook 7H11 agar supplemented with OADC. Bacterial suspensions used in subsequent assays were prepared by resuspending single colonies of each strain into $1 \mathrm{ml}$ of sterile distilled water.

Drug susceptibility testing was repeated using phenotypic and genotypic approaches; Middlebrook 7H10 agar proportion method and line probe assays (Genotype MTBDRplus, Hain Life Sciences, Germany), respectively. With both methods all the isolates were confirmed to be fully susceptible to Isoniazid and Rifampicin.

\section{Genotyping}

Chromosomal DNA used as templates in PCRs was prepared as previously described [17]. Similarly, the M. tuberculosis spoligotypes were determined by Spoligotyping as recently described [6]. The isolates were re-genotyped using MIRU-VNTR [17] and SNP-based Real-Time PCR [8] to confirm that they belong to M. tuberculosis Beijing, Uganda II and Delhi/CAS families.

\section{Determination of minimum inhibitory concentrations}

Isoniazid and Rifampicin were purchased from SigmaAldrich (St. Louis, MO). Stock concentrations at $10 \mathrm{mg} / \mathrm{ml}$ were prepared using either sterile distilled water (Rifampicin) or Dimethyl Sulphoxide (DMSO) (Isoniazid). To determine the minimum inhibitory concentrations (MICs), microdilution plate assays were performed as described by Wallace et al., 1986 [18] and Lenaerts et al., 2005 [19]. Bacterial suspensions were adjusted to McFarland standard of $0.5,100 \mu \mathrm{l}$ of which were inoculated into $11 \mathrm{ml}$ Middlebrook 7H9 medium supplemented with glycerol and OADC, to give a desired inoculum of $1 \times 10^{5}$ colony forming units (CFU) per ml.

Microtitre plate wells were seeded with $98 \mu \mathrm{l}$ of the bacterial suspension, into which $2 \mu \mathrm{l}$ of drug was added. The final concentration of drugs ranged from 0.03$4.0 \mu \mathrm{g} / \mathrm{ml}$ (Isoniazid) and 0.12-16 $\mu \mathrm{g} / \mathrm{ml}$ (Rifampicin). Control wells contained only DMSO or water. The outer wells of the plates were filled with water to avoid evaporation from the sample wells. The plates were sealed with perforated parafilm and incubated at $37{ }^{\circ} \mathrm{C}$ for 21 days. Plates were observed weekly to monitor changes in growth. Growth inhibition was determined by visual examination. The MIC was determined as the lowest drug concentration with no visible bacterial growth after 3 weeks of incubation. Duplicate MICs per strain were determined. In all assays the $M$. tuberculosis reference strain, H37Rv, was used as the control.

\section{Determination of killing curves under aerobic conditions}

The MICs above were used to calculate the final drug concentration per strain that was used in determining killing curves. The bacterial suspensions were adjusted to an inoculum of $\log _{10} 7.0 \mathrm{CFU} / \mathrm{ml}$ (range of $\log _{10}$ 6.9-8.2 CFU/ml), as described above. To the bacterial suspension, drugs were added to final concentrations of; 1x MIC, 2x MIC and 5x MIC, and incubated at $37{ }^{\circ} \mathrm{C}$. As such, the concentrations for Isoniazid were: $0.5 \mu \mathrm{g} / \mathrm{ml}$ (1x MIC), $1 \mu \mathrm{g} / \mathrm{ml}(2 \mathrm{x}$ MIC) and $2.5 \mu \mathrm{g} / \mathrm{ml}$ (5x MIC) for Uganda II; $0.03 \mu \mathrm{g} / \mathrm{ml}$ (1x MIC), $0.06 \mu \mathrm{g} / \mathrm{ml}$ (2x MIC) and $0.15 \mu \mathrm{g} / \mathrm{ml}$ (5x MIC) for both Beijing and Delhi/CAS. Further, the concentrations for Rifampicin were: $1 \mu \mathrm{g} / \mathrm{ml}$ (1x MIC), $2 \mu \mathrm{g} / \mathrm{ml}$ (2x MIC) and $5 \mu \mathrm{g} / \mathrm{ml}(5 \mathrm{x} M I C)$ for Uganda II; $0.12 \mu \mathrm{g} / \mathrm{ml}(1 \mathrm{x} \quad \mathrm{MIC}), \quad 0.24 \mu \mathrm{g} / \mathrm{ml} \quad(2 \mathrm{x} \quad \mathrm{MIC})$ and $0.6 \mu \mathrm{g} / \mathrm{ml}$ (5x MIC) for both Beijing and Delhi/CAS.

The day on which the drug was added to the cultures was defined as day 0 and the corresponding CFUs were taken as $100 \%$. On days $0,2,4,6,8$ and 10 , one milliliter was drawn from each tube and serially diluted with sterile distilled water. One hundred microliters of the diluted culture was plated onto Middlebrook $7 \mathrm{H} 11$ agar supplemented with OADC, and incubated at $37{ }^{\circ} \mathrm{C}$ under normal atmospheric conditions. After 21 days, $\mathrm{CFUs} / \mathrm{ml}$ were determined and were used to calculate the $\log _{10} \mathrm{CFUs} / \mathrm{ml}$.

\section{Determination of killing curves under oxygen depleted conditions}

We employed Wayne's model as described by MurugasuOei et al., 2000 [20] with a few modifications to suit our setting. Bacterial suspensions were prepared as explained above. Tubes were closed with sterile silicone rubber septa, and incubated at $37^{\circ} \mathrm{C}$ with slow stirring for 24 days. Control tubes, in addition to the culture, contained the Methylene Blue dye $(1.5 \mathrm{~g} / \mathrm{ml})$, which was used as an indicator of oxygen depletion. The blue dye faded and disappeared indicating that oxygen is successfully depleted in the culture, as described by Wayne and Hayes, 1996 [21]. The drugs were injected into cultures through the septa on day 24 at concentrations based on MICs. Controls had no drug but water or DMSO. The cultures were incubated at $37^{\circ} \mathrm{C}$ for 10 days.

On days $0,2,4,6,8$ and 10 , one milliliter from each tube was serially diluted in sterile distilled water, and $100 \mu \mathrm{l}$ of the diluted culture incubated at $37{ }^{\circ} \mathrm{C}$ on Middlebrook 7H11 agar plates supplemented with OADC under normal atmospheric conditions. Colonies were counted after 21 days. 


\section{Data analysis}

To test the hypothesis that there is a difference in response to anti-TB drugs between $M$. tuberculosis Uganda and other families, data were analyzed with the Student's $\mathrm{t}$-distribution test to compare responses of $M$. tuberculosis Uganda II vs. Beijing, and Uganda II vs. Delhi/CAS. The means of the different killing curves were compared and a $p$-value of $<0.05$ at $95 \% \mathrm{CI}$ and $\alpha=0.05$ was considered significant. The data was analyzed with GraphPad Prism statistical program version 5 .

\section{Definitions}

In this study, strain refers to any of the seven MTBC lineages [3] or sub-lineages; hence, strain = lineage/sub-lineage.

\section{Results}

Minimum inhibitory concentrations

The MIC for Isoniazid was $0.05 \mu \mathrm{g} / \mathrm{ml}$ for $M$. tuberculosis Uganda II, and $0.03 \mu \mathrm{g} / \mathrm{ml}$ for both Beijing and Delhi/CAS families. Rifampicin MIC was $1 \mu \mathrm{g} / \mathrm{ml}$ for $M$. tuberculosis Uganda II, and $0.12 \mu \mathrm{g} / \mathrm{ml}$ for both Beijing and Delhi/ CAS. Thus, compared with the other two strains, $M$. tuberculosis Uganda II required higher Isoniazid and Rifampicin concentrations to inhibit its growth.

\section{Isoniazid is more effective under aerobic conditions than oxygen-depleted conditions}

Under aerobic and oxygen depleted conditions, the $\mathrm{CFU} / \mathrm{ml}$ of control cultures (no Isoniazid added) increased from days 0 to 10 , Fig. 1 . For instance, on day 0 the $\log _{10} \mathrm{CFU} / \mathrm{ml}$ for $M$. tuberculosis Uganda II control was 7.8; it increased to 9.4 and 10.2 on days 4 and 10, respectively. On adding Isoniazid to cultures, CFUs/ml reduced both at low and high concentrations under aerobic conditions, Fig. 1. However, on adding Isoniazid under oxygen depleted conditions, CFUs/ml did not markedly reduce, Fig. 1. Hence, Isoniazid effectively killed more under aerobic conditions than under oxygen-depleted conditions. Table 1 shows the mean bacterial counts $\left(\log _{10} \mathrm{CFU} / \mathrm{ml}\right)$ after 10 day exposure to Isoniazid and Rifampicin.

Furthermore, under aerobic conditions comparison of the mean $\log _{10}$ MICs of the pairs of killing curves for M. tuberculosis Uganda II vs. Beijing; M. tuberculosis Uganda II vs. Delhi/CAS was not statistically significant at all Isoniazid concentrations tested ( $p$-value $>0.05)$, Table 2. Likewise, under oxygen depleted conditions at low Isoniazid concentrations (1x MIC, $2 x \mathrm{MIC}$ ), the differences in mean $\log _{10}$ MICs of the pairs of killing curves for M. tuberculosis Uganda II vs. Beijing; M. tuberculosis Uganda II vs. Delhi/CAS was not statistically significant ( $p$-value >0.05), Table 2 . The exception was $5 \mathrm{x}$ MIC Isoniazid under oxygen depleted conditions, where we found the difference in mean $\log _{10}$ MICs between $M$. tuberculosis Uganda II vs. Beijing to be statistically significant $(p$-value $=0.02,95 \%$ CI 0.019-0.169), Table 2 .

\section{Rifampicin is more effective than Isoniazid at killing $M$. tuberculosis under oxygen-depleted conditions}

Similar to Isoniazid, the CFU/ml of controls where no Rifampicin was added, increased from days 0 to 10 both under aerobic and oxygen depleted conditions, Fig. 2. However, in contrast to Isoniazid, Rifampicin reduced the CFUs beyond day 0 under both aerobic and oxygen depleted conditions, Fig. 2. This result was more pronounced at high Rifampicin concentrations (2x MIC, 5x MIC) under oxygen depleted conditions, Fig. 2. Overall, both drugs were more effective at killing the bacilli under aerobic conditions compared to oxygen depleted conditions, although this difference was more pronounced for
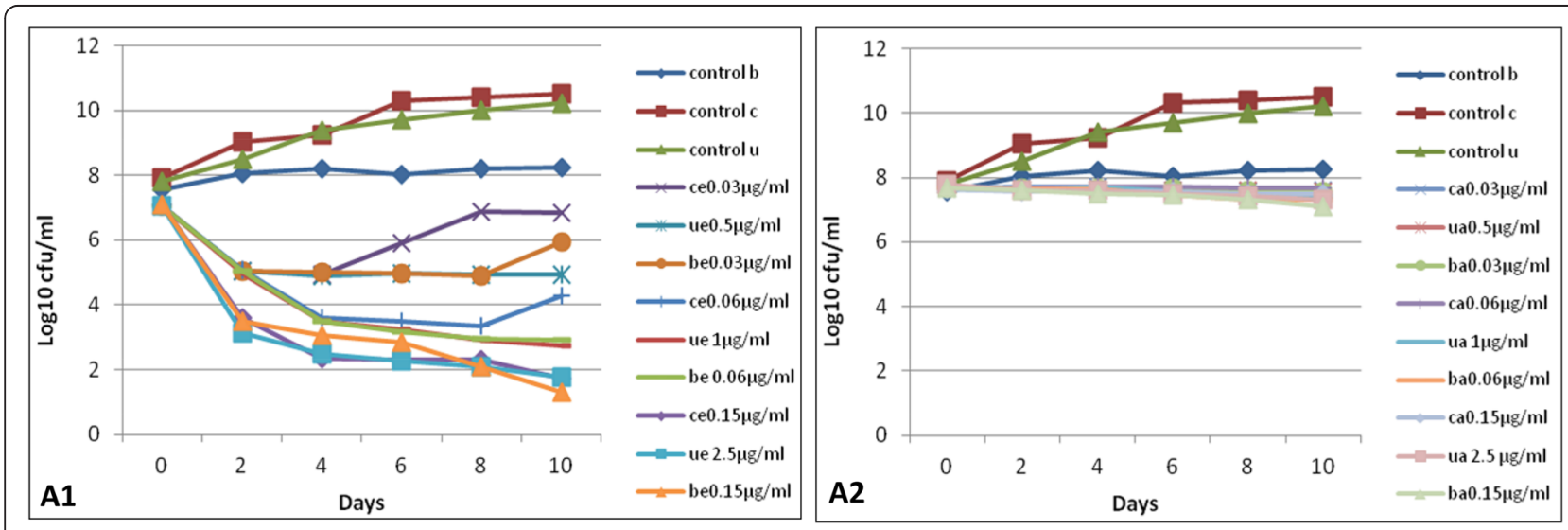

Fig. 1 The effect of Isoniazid on M. tuberculosis Uganda II, Beijing and Delhi/CAS. Panel A1, aerobic conditions. control b, Beijing with no drug; control

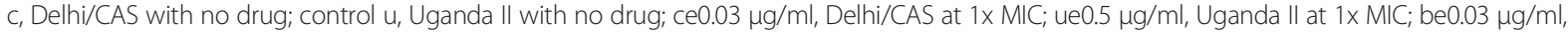

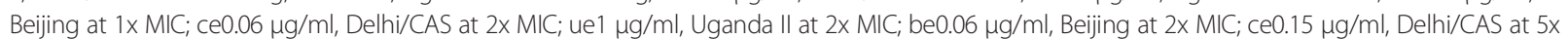

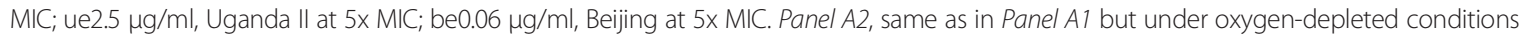


Table 1 Mean counts ( $\log _{10}$ CFU/ml) after 10-day exposure to Isoniazid and Rifampicin

\begin{tabular}{|c|c|c|c|c|c|c|c|c|c|c|c|c|}
\hline \multirow{3}{*}{$\begin{array}{l}\text { Strain/ } \\
\text { genotype }\end{array}$} & \multicolumn{6}{|c|}{ Isoniazid } & \multicolumn{6}{|c|}{ Rifampicin } \\
\hline & \multicolumn{3}{|l|}{ Aerobic } & \multicolumn{3}{|c|}{ Oxygen depleted } & \multicolumn{3}{|l|}{ Aerobic } & \multicolumn{3}{|c|}{ Oxygen depleted } \\
\hline & $1 \times \mathrm{MIC}$ & $2 \times \mathrm{MIC}$ & $5 \times \mathrm{MIC}$ & $1 \times \mathrm{MIC}$ & $2 \times \mathrm{MIC}$ & $5 \times \mathrm{MIC}$ & $1 \times \mathrm{MIC}$ & $2 \times \mathrm{MIC}$ & $5 \times \mathrm{MIC}$ & $1 \times \mathrm{MIC}$ & $2 \times \mathrm{MIC}$ & $5 \times \mathrm{MIC}$ \\
\hline Uganda II & 5.29 & 4.06 & 3.12 & 7.51 & 7.56 & $7.22^{*}$ & 5.45 & 4.11 & 2.86 & 5.03 & $3.91^{*}$ & $3.03^{*}$ \\
\hline Delhi/CAS & 6.10 & 4.47 & 3.23 & 7.64 & 7.67 & 7.49 & 5.27 & 2.96 & 2.96 & 7.43 & $6.58^{*}$ & $5.23^{*}$ \\
\hline Beijing & 5.48 & 4.10 & 3.30 & 7.64 & 7.51 & $7.36^{*}$ & 5.44 & 2.93 & 2.93 & 7.39 & 6.53 & $5.14^{*}$ \\
\hline
\end{tabular}

*Where $P$-value was $<0.05$ when compared to Uganda II

Isoniazid. Thus, compared to Isoniazid, Rifampicin had more killing ability of $M$. tuberculosis irrespective of strain or genotype under oxygen depleted conditions.

Similarly for Rifampicin at low concentrations under aerobic conditions, analysis of the pairs of the killing curves for $M$. tuberculosis Uganda II vs. Beijing; $M$. tuberculosis Uganda II vs. Delhi/CAS did not show significant difference in the means ( $p$-value >0.05), Table 2 . Also, under oxygen depleted conditions at 1x MIC Rifampicin concentration there was no significant difference in the killing curves ( $p$-value $>0.05)$. However, in contrast to Isoniazid, Rifampicin showed more pairs under oxygen depleted conditions, with significant differences in mean MICs even at 2x MIC; $M$. tuberculosis Uganda II vs. Delhi/CAS ( $p$-value $=0.01,95 \%$ CI $0.009-0.063$ at $2 \mathrm{x}$ MIC; $p$-value $=0.005,95 \% \mathrm{CI}$ 0.997-3.463 at 5x MIC); M. tuberculosis Uganda II vs. Beijing ( $p$-value $=0.004,95 \%$ CI $-3.277-0.966)$ at $5 \mathrm{x}$ MIC, Table 2.

Taken together, these data show that $M$. tuberculosis Uganda II is more susceptible to Isoniazid and Rifampicin than Beijing or Delhi/CAS families, particularly at high drug concentrations under oxygen depletion.

\section{Discussion}

We have investigated drug-resistance and virulence as factors associated with the predominance of the $M$. tuberculosis Uganda family in Uganda. In one of the studies, we found that the M. tuberculosis Uganda family is three times less likely to be resistant to first-line anti-TB drugs and five times less likely to be multidrug resistant, compared to the non-Uganda II families [5]. Furthermore, in the other study investigating virulence we found that the $M$. tuberculosis Uganda family was less virulent as defined by cavitary disease [8]. Although response to first-line anti-TB drugs would offer a better explanation to predominance, in this study, we have found no significant differences in the susceptibility patterns between $M$. tuberculosis Uganda II vs. Beijing or Delhi/CAS families, except at high drug concentrations under oxygen-depleted conditions where the Uganda II family was instead more susceptible to Rifampicin and Isoniazid than the Beijing or Delhi/CAS families. Therefore, in line with recent studies [4-6], the predominance of M. tuberculosis Uganda family in Uganda may not be attributed to its susceptibility behavior once exposed to Isoniazid and Rifampicin.

Table 2 Analysis of pairs of killing curves for M. tuberculosis Uganda II vs. Beijing, and M. tuberculosis Uganda II vs. Delhi/CAS

\begin{tabular}{|c|c|c|c|c|}
\hline & & $\begin{array}{l}1 \times \text { MIC }(U g-0.5 \mu g / m l, B e-0.03 \\
\mu \mathrm{g} / \mathrm{ml}, \mathrm{Ce}-0.03 \mu \mathrm{g} / \mathrm{ml})\end{array}$ & $\begin{array}{l}2 \times \mathrm{MIC}(\mathrm{Ug}-1 \mu \mathrm{g} / \mathrm{ml}, \mathrm{Be}-0.06 \\
\mu \mathrm{g} / \mathrm{ml}, \mathrm{Ce}-0.24 \mu \mathrm{g} / \mathrm{ml})\end{array}$ & $\begin{array}{l}5 x \mathrm{MIC}(\mathrm{Ug}-0.25 \mu \mathrm{g} / \mathrm{ml}, \mathrm{Be}-0.15 \\
\mu \mathrm{g} / \mathrm{ml}, \mathrm{Ce}-0.15 \mu \mathrm{g} / \mathrm{ml})\end{array}$ \\
\hline Drug (condition) & Strain & $p$-value, mean of diffs (95\% Cl) & $p$-value, mean of diffs (95\% Cl) & $p$-value, mean of diffs ( $95 \% \mathrm{Cl}$ ) \\
\hline \multirow[t]{2}{*}{ INH (aerobic) } & Ug vs Be & $0.30,-0.191(-0.623-0.241)$ & $0.40,-0.034(-0.133-0.635)$ & $0.33,-0.176(-0.602-0.250)$ \\
\hline & Ug vs Ce & $0.09,0.809(-0.187-1.806)$ & $0.14,0.408(-0.199-1.016)$ & $0.30,0.103(-0.128-0.334)$ \\
\hline \multirow[t]{3}{*}{ INH $\left(\mathrm{O}_{2}\right.$ depletion $)$} & Ug vs Be & $0.13,-0.023(-0.057-0.010)$ & $0.17,0.053(-0.032-0.138)$ & $0.02,0.094(0.019-0.169)^{*}$ \\
\hline & Ug vs Ce & $0.20,0.025(-0.018-0.069)$ & $0.14,0.408(-0.199-1.016)$ & $0.55,0.027(-0.083-0.137)$ \\
\hline & & $\begin{array}{l}1 \times \text { MIC }(U g-1 \mu g / m l, B e-0.121 \\
\mu g / m l, C e-0.12 \mu g / m l)\end{array}$ & $\begin{array}{l}\text { 2x MIC (Ug-2 } \mu \mathrm{g} / \mathrm{ml} /, B e-0.24 \\
\mu \mathrm{g} / \mathrm{ml}, \mathrm{Ce}-0.24 \mu \mathrm{g} / \mathrm{ml})\end{array}$ & $\begin{array}{l}5 \times \mathrm{MIC}(\mathrm{Ug}-5 \mu \mathrm{g} / \mathrm{ml}, \text { Be-0.6 } \\
\mu \mathrm{g} / \mathrm{ml}, \mathrm{Ce}-0.6 \mu \mathrm{g} / \mathrm{ml})\end{array}$ \\
\hline \multirow[t]{2}{*}{ RIF (aerobic) } & Ug vs Be & $0.93,0.006(-0.162-0.174)$ & $0.12,-0.427(1.025-0.169)$ & $0.60,-0.603(-0.603-0.391)$ \\
\hline & Ug vs Ce & $0.34,-0.176(-0.617-0.263)$ & $0.07,0.485(-0.081-1.052)$ & $0.49,0.140(-0.348-0.629)$ \\
\hline \multirow[t]{2}{*}{$\operatorname{RIF}\left(\mathrm{O}_{2}\right.$ depletion) } & Ug vs Be & $0.51,-0.040(-0.187-0.107)$ & $0.36,0.011(-0.018-0.041)$ & $0.004,-2.137(-3.277-0.996)^{*}$ \\
\hline & Ug vs Ce & $0.13,0.073(-0.033-0.179)$ & $0.01,0.036(0.009-0.063)^{*}$ & $0.005,2.230(0.997-3.463)^{*}$ \\
\hline
\end{tabular}

MIC, minimum inhibitory concentration; Ug, Uganda II; Ce, Delhi/CAS; Be, Beijing INH, Isoniazid; RIF, Rifampicin;

${ }^{*} P$-value $<0.05$ 

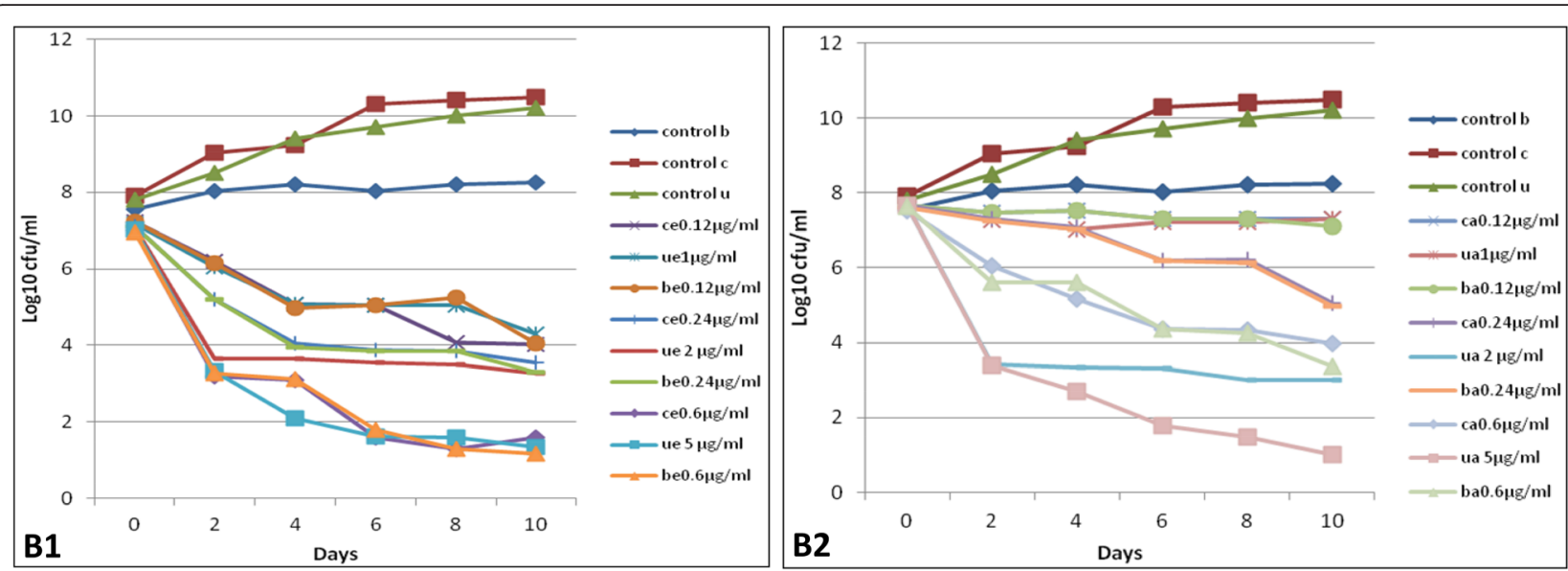

Fig. 2 The effect of Rifampicin on M. tuberculosis Uganda II, Beijing and Delhi/CAS. Panel B1, aerobic conditions. control b, Beijing with no drug; control c, Delhi/CAS with no drug; control u, Uganda II with no drug; ce0.12 $\mu \mathrm{g} / \mathrm{ml}$, Delhi/CAS at 1x MIC; ue1 $\mu \mathrm{g} / \mathrm{ml}$, Uganda II at 1x MIC;

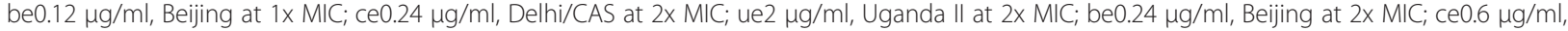
Delhi/CAS at $5 \times$ MIC; ue $5 \mu \mathrm{g} / \mathrm{ml}$, Uganda II at $5 x$ MIC; be0.6 $\mu \mathrm{g} / \mathrm{ml}$, Beijing at $5 \times$ MIC. Panel B2, same as in Panel B1 but under oxygen-depleted conditions

The MICs for Rifampicin and Isoniazid showed that the strains were fully susceptible to both drugs and the killing curve phenomenon could be demonstrated. The MICs for Isoniazid were in agreement with previous reports [22] of $0.02-0.05 \mathrm{mg} / \mathrm{ml}$ and were equally effective against all the three MTBC strains. Also, the MICs for Rifampicin were in agreement with the previous study [23] that reported $0.25-0.5 \mathrm{mg} / \mathrm{L}$ and $1 \mathrm{mg} / \mathrm{L}$ using agar proportion method and micro-dilution resazurin assay, respectively, for $M$. tuberculosis laboratory strain H37Rv commonly used as the reference for in vitro studies, and 0.0625-0.125 $\mathrm{mg} / \mathrm{L}$ for susceptible clinical isolates.

Generally under oxygen-depleted conditions, the less predominant strains (M. tuberculosis Beijing and Delhi/ CAS families) were less susceptible at the highest test concentrations of Isoniazid and Rifampicin $(1.25 \mu \mathrm{g} / \mathrm{ml}$ and $5 \mu \mathrm{g} / \mathrm{ml}$, respectively). These strains had lower MICs than $M$. tuberculosis Uganda II and probably respond better in vivo where drug concentrations are higher than the ones studied. Nevertheless, our test concentrations are still lower than the peak concentrations of both drugs in serum $(3-7 \mu \mathrm{g} / \mathrm{mL}$ and $6-9 \mu \mathrm{g} / \mathrm{mL}$ for isoniazid and rifampicin, respectively) [24], implying that different responses may occur in vivo.

Although Isoniazid showed high and rapid activity against replicating mycobacteria under aerobic conditions, compared to Rifampicin, it exhibited poor activity against them under conditions of low oxygen tension. Increasing the drug concentrations did not change this observation. This could be attributed to the fact that Isoniazid targets Mycobacterium's cell wall synthesis [19] and is therefore more effective against actively replicating bacteria. The rapid activity of Isoniazid is further supported by similar findings of de Steenwinkel et al., 2010, where it also showed extremely rapid and concentration-dependent killing while Rifampicin had relatively slow and strongly time-dependent killing [14]. Furthermore, at low drug concentrations we noted no significant difference in the way the three strains responded to Isoniazid and Rifampicin under aerobic conditions. This agrees with findings by Lenaert et al., 2005, where Isoniazid showed little activity against the non-replicating bacteria even when $2 \mu \mathrm{g} / \mathrm{ml}, 10 \mu \mathrm{g} / \mathrm{ml}$, and $50 \mu \mathrm{g} / \mathrm{ml}$ concentrations were used [19]. On the other hand, Rifampicin showed a better activity than Isoniazid at all concentrations tested under conditions of low oxygen tension. This is supported by Lenaert et al., 2005 findings, where $2 \mu \mathrm{g} / \mathrm{ml}, 10 \mu \mathrm{g} / \mathrm{ml}$ and $50 \mu \mathrm{g} / \mathrm{ml}$ of Rifampicin was very effective against non-replicating $M$. tuberculosis grown under conditions of oxygen depletion [19]. This is because Rifampicin targets protein synthesis and is therefore active against non-replicating bacteria or low metabolizing bacteria [19] where it inhibits RNA synthesis by inhibiting DNA-dependent RNA polymerase [25].

The inactive state of the tubercle bacilli was achieved as described by Wayne and Hayes, 1996, resulting in a state known as non-replicating phase 2 (NRP-2) of low metabolic rate that is experienced during the conditions of low oxygen tension [21]. However, apart from using Methylene Blue dye to indicate that the low oxygen level condition is achieved, we could not accurately measure the level of oxygen tension [21].

In Uganda, latent and active TB are treated with similar drug regimen irrespective of the strain causing disease in the host. Given our findings, one can infer that there is no need of genotyping the infecting strain of a 
patient before starting treatment or when judging prophylaxis, since there is no significant difference in killing. However, further research into this is required to enable detailed comparisons; testing more strains at wider range of drug concentrations that put into consideration the serum levels achieved during treatment is recommended.

\section{Conclusions}

At low Rifampicin and Isoniazid concentrations under aerobic conditions, there is no difference in susceptibility patterns between $M$. tuberculosis Uganda II and Beijing or Delhi/CAS families. At high concentrations of the same drugs under oxygen-depleted conditions, $M$. tuberculosis Uganda II is more susceptible to Rifampicin and Isoniazid compared to Beijing or Delhi/CAS families. Therefore, the predominance of the $M$. tuberculosis Uganda II family as the main causative agent of TB in Uganda cannot be attributed to its susceptibility behavior as judged from the three selected strains. Probably, its predominance is due to differences in the immune defenses in the general population against the strains, given that the M. tuberculosis Beijing and Delhi/CAS families are likely to have been introduced more recently. Further research beyond susceptibility to anti-TB drugs is required to ascertain these.

\section{Ethics statement}

This study was nested within previously approved studies $[8,17]$ that obtained approval from the Joint Clinical Research Centre Kampala, the University Hospitals Cleveland Institutional Review Board (Cleveland Ohio), and Makerere University School of Medicine Institutional Review Boards. Informed written consent (including the use of samples in further studies) was obtained from patients who participated in the study. The study was also reviewed and approved by the Higher Degrees Research Committee of the College of Veterinary Medicine, Animal Resources and Biosecurity, Makerere University. The $M$. tuberculosis test isolates in this study were originally cultured from collected human samples.

\section{Availability of data and materials}

The datasets supporting the conclusions of this article are included within the article.

\footnotetext{
Abbreviations

$\mathrm{Cl}$ : confidence interval; JCRC: joint clinical research center; MIC: minimum inhibitory concentration; MRA: micro-dilution resazurin assay; NRP-2: non-replicating phase 2; NTRL: national tuberculosis reference Laboratory; OADC: Oleic Albumin Dextrose Catalase; PCR: polymerase chain reaction.
}

\section{Competing interests}

The authors declare that they have no competing interests.

\section{Authors' contributions}

MLJ conceived the study. GWK performed the experiments, statistical analysis and drafted the manuscript. DPK, MLJ and GWK participated in study design and coordination, wrote the final manuscript and handled the submission and review process. All authors read and approved the final manuscript.

\section{Acknowledgements}

We thank the staff and management of the Uganda National TB Reference laboratory, JCRC and Medical \& Molecular laboratory for providing the study isolates and helping with the experimental procedures.

\section{Funding}

There was no funding for this study.

\section{Author details}

${ }^{1}$ National Tuberculosis and Leprosy Program, Kampala, Uganda. ${ }^{2}$ National TB Reference Laboratory, Kampala, Uganda. ${ }^{3}$ Department of Immunology and Molecular Biology, College of Health Sciences, Makerere University, Kampala, Uganda. ${ }^{4}$ Department of Medical Microbiology, College of Health Sciences, Makerere University, Kampala, Uganda.

Received: 29 July 2015 Accepted: 29 March 2016

Published online: 21 April 2016

\section{References}

1. Gagneux S. Host-pathogen coevolution in human tuberculosis. Philos Trans R Soc Lond Ser B Biol Sci. 2012;367(1590):850-9.

2. Asante-Poku A, Yeboah-Manu D, Otchere ID, Aboagye SY, Stucki D, Hattendorf J, Borrell S, Feldmann J, Danso E, Gagneux S. Mycobacterium africanum is associated with patient ethnicity in Ghana. PLoS Negl Trop Dis. 2015:9(1):e3370.

3. Gagneux S, Small PM. Global phylogeography of Mycobacterium tuberculosis and implications for tuberculosis product development. Lancet Infect Dis. 2007;7(5):328-37.

4. Asiimwe B, Koivula T, Källenius G, Huard R, Ghebremichael S, Asiimwe J, Joloba M. Mycobacterium tuberculosis Uganda genotype is the predominant cause of TB in Kampala, Uganda. Int J Tuberc Lung Dis. 2008;12(4):386-91.

5. Ezati N, Lukoye D, Wampande EM, Musisi K, Kasule GW, Cobelens FG, Kateete DP, Joloba ML. The Mycobacterium tuberculosis Uganda II family and resistance to first-line anti-tuberculosis drugs in Uganda. BMC Infect Dis. 2014;14(1):703.

6. Lukoye D, Katabazi FA, Musisi K, Kateete DP, Asiimwe BB, Moses O, Joloba ML, Cobelens FG. The T2 Mycobacterium tuberculosis Genotype, Predominant in Kampala-Uganda, Shows Negative Correlation with anti-Tuberculosis Drug Resistance. Antimicrob Agents Chemother. 2014;58(7):3853-9.

7. Nabyonga L, Kateete DP, Katabazi FA, Odong PR, Whalen CC, Dickman KR, Moses JL. Determination of circulating Mycobacterium tuberculosis strains and transmission patterns among pulmonary TB patients in Kawempe municipality, Uganda, using MIRU-VNTR. BMC Res Notes. 2011:4(1):280.

8. Wampande EM, Mupere E, Debanne SM, Asiimwe BB, Nsereko M, Mayanja H, Eisenach K, Kaplan G, Boom HW, Gagneux S, et al. Long-term dominance of Mycobacterium tuberculosis Uganda family in peri-urban Kampala-Uganda is not associated with cavitary disease. BMC Infect Dis. 2013;13:484.

9. McKinney JD, zu Bentrup KH, Muñoz-Elías EJ, Miczak A, Chen B, Chan W-T, Swenson D, Sacchettini JC, Jacobs WR, Russell DG. Persistence of Mycobacterium tuberculosis in macrophages and mice requires the glyoxylate shunt enzyme isocitrate lyase. Nature. 2000;406(6797):735-8.

10. Elliott A, Beming S, Iseman M, Peloquin C. Failure of drug penetration and acquisition of drug resistance in chronic tuberculous empyema. Tuber Lung Dis. 1995;76(5):463-7.

11. CANETTI G. Thé Tubercle Bacillus in the Pulmonary Lesion of Man. Histobacteriology and its Bearing on the Therapy of Pulmonary Tuberculosis Foreword by Rene J DUBOS \& Walsh MCDERMOTT 1955.

12. Canetti G: The tubercle bacillus in the pulmonary lesion of manSpringer. New York 1955

13. Wayne L. Dormancy of Mycobacterium tuberculosis and latency of disease. Eur J Clin Microbiol Infect Dis. 1994;13(11):908-14.

14. de Steenwinkel JE, de Knegt GJ, Marian T, van Belkum A, Verbrugh HA, Kremer K, van Soolingen D, Bakker-Woudenberg IA. Time-kill kinetics of anti-tuberculosis drugs, and emergence of resistance, in relation to metabolic activity of Mycobacterium tuberculosis. J Antimicrob Chemother. 2010;65(12):2582-9. 
15. Amsterdam D. Susceptibility testing of antimicrobials in liquid media. Antibiot Lab Med. 1996;4:52-111.

16. Guerillot F, Carret G, Flandrois J. Mathematical model for comparison of time-killing curves. Antimicrob Agents Chemother. 1993;37(8):1685-9.

17. Dickman KR, Nabyonga L, Kateete DP, Katabazi FA, Asiimwe BB, Mayanja HK, Okwera A, Whalen C, Joloba ML. Detection of multiple strains of Mycobacterium tuberculosis using MIRU-VNTR in patients with pulmonary tuberculosis in Kampala, Uganda. BMC Infect Dis. 2010;10:349.

18. Wallace R, Nash DR, Steele LC, Steingrube V. Susceptibility testing of slowly growing mycobacteria by a microdilution MIC method with 7 H9 broth. J Clin Microbiol. 1986;24(6):976-81.

19. Lenaerts AJ, Gruppo V, Marietta KS, Johnson CM, Driscoll DK, Tompkins NM, Rose JD, Reynolds RC, Orme IM. Preclinical testing of the nitroimidazopyran PA-824 for activity against Mycobacterium tuberculosis in a series of in vitro and in vivo models. Antimicrob Agents Chemother. 2005:49(6):2294-301.

20. Murugasu-Oei B, Dick T. Bactericidal activity of nitrofurans against growing and dormant Mycobacterium bovis BCG. J Antimicrob Chemother. 2000;46(6):917-9.

21. Wayne $L G$, Hayes $L G$. An in vitro model for sequential study of shiftdown of Mycobacterium tuberculosis through two stages of nonreplicating persistence. Infect Immun. 1996;64(6):2062-9.

22. Whitney JB, Wainberg MA. Isoniazid, the frontline of resistance in Mycobacterium tuberculosis. McGill J Med. 2002;6(2):114-23.

23. Banfi E, Scialino G, Monti-Bragadin C. Development of a microdilution method to evaluate Mycobacterium tuberculosis drug susceptibility. J Antimicrob Chemother. 2003;52(5):796-800.

24. Venkatesan K. Clinical pharmacokinetic considerations in the treatment of patients with leprosy. Clin Pharmacokinet. 1989;16(6):365-86.

25. Calvori C, Frontali L, Leoni L, Tecce G. Effect of rifamycin on protein synthesis. Nature. 1965;207:417-8.

\section{Submit your next manuscript to BioMed Central and we will help you at every step:}

- We accept pre-submission inquiries

- Our selector tool helps you to find the most relevant journal

- We provide round the clock customer support

- Convenient online submission

- Thorough peer review

- Inclusion in PubMed and all major indexing services

- Maximum visibility for your research

Submit your manuscript at www.biomedcentral.com/submit

C Biomed Central 